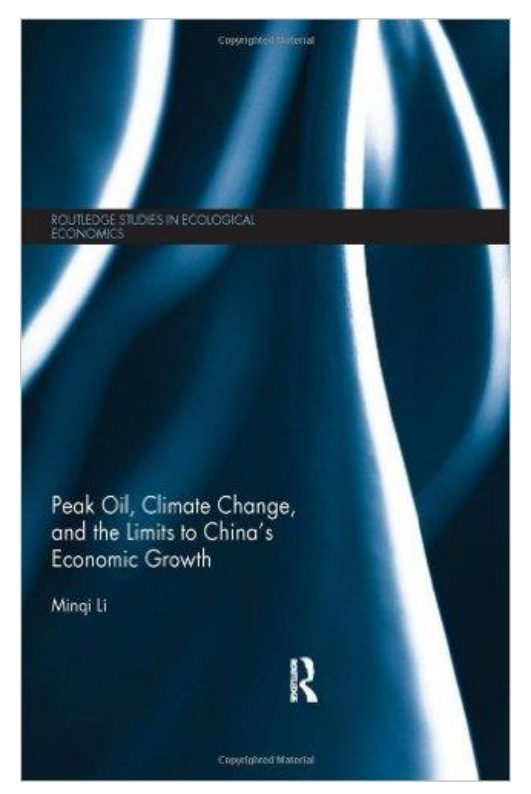

\title{
Resenha
}

\section{Peak oil, climate change, and the limits to China's economic growth}

Minqi L. Peak oil, climate change, and the limits to China's economic growth. New York: Routledge, 2014. 192 p.

\section{Henrique Morrone*}

\section{Introdução}

O livro Pico do Petróleo, Mudança Climática e os Limites do Crescimento Econômico Chinês (em Inglês: Peak Oil, Climate Change, and the Limits to China's Economic Growth), de Minqi Li, professor de Economia da Universidade de Utah (EUA), aborda um tema crucial à teoria do crescimento econômico: o limite imposto pela natureza ao sistema capitalista, com foco no papel hegemônico que será desenvolvido pela China. Especificamente, o autor, por meio das abordagens marxista e de sistemas mundo (desenvolvida por Immanuel Wallerstein e Giovanni Arrighi) consegue transmitir de forma clara e rigorosa os limites impostos à dinâmica capitalista, representados pela exaustão de combustíveis fósseis e os requerimentos para a estabilização climática. O tema é caro ao autor, sendo uma de suas principais linhas de pesquisa. Seu vasto conhecimento sobre o tópico fica demonstrado pelo número de referências bibliográficas ao longo do trabalho.

O livro tem como objetivo investigar como o esgotamento dos combústiveis fósseis e a estabilização climática limitarão o crescimento econômico global, com atenção especial à 
economia chinesa. Ademais, o autor busca averiguar o potencial das energias renováveis e dos ganhos de eficiência energética para promover crescimento econômico e sustentabilidade climática.

Empregando o instrumental marxista, o autor projeta que tanto as energias renováveis como a eficiência energética serão insuficientes para engendrar crescimento econômico aos moldes necessários para a estabilidade política e social do capitalismo. Nesse sentido, a tese principal do autor é de que existe uma contradição fundamental entre o sistema mundial capitalista, baseado na acumulação de capital e na busca por lucros crescentes, e os requerimentos para a sustentabilidade ecológica.

Buscando atingir esses objetivos, professor Li estrutura sua obra em três grandes blocos (ou partes). O primeiro, formado pelos Capítulos 1, 2 e 3, estabelece as bases teóricas para o restante do livro. O capítulo 1 oferece uma introdução, abordando aspectos conceituais, bem como a tese principal do autor. $\mathrm{O}$ capítulo 2 fornece as bases históricas para a evolução do sistema capitalista mundial e à dinâmica chinesa. Estatísticas sobre o consumo de energia mundial e chinesa são apresentadas no Capiítulo 3. Além disso, também são introduzidos conceitos importantes para a compreensão dos capítulos subsequentes. O segundo bloco (formado pelos Capítulos 4, 5, e 6) aprofunda o exame da questão energética no mundo, e em particular na China. Questões como picos na produção de petróleo, o exame das fontes de petróleo e projeções da demanda e oferta energética são tratadas nesses capítulos. Por fim, a parte restante do livro (Capítulos 7, 8, e 9) expõe as contradições econômicas, sociais, e ecológicas do sistema capitalista mundial, projetando uma crise estrutural da economia chinesa e mundial nas próximas décadas. Ademais, esses capítulos indicam que somente uma economia global com crescimento em estado estacionário (taxa de crescimento zero) seria compatível com a estabilidade climática, o que vai de encontro às forças motoras do sistema capitalista. Assim, não haveria solução para o sistema mundial a não ser a troca do regime para um sistema compatível com crescimento nulo.

\section{Estrutura do livro}

O livro está estruturado em nove capítulos. Neste livro, professor Li dá continuidade ao seu projeto anterior, intitulado The Rise of China and the Demise of the Capitalist World Economy, com foco especial na questão da contradição entre crescimento capitalista e estabilidade climática. 
No primeiro capítulo, intitulado Peak Oil, Climate Change, and China, o autor apresenta as ideias básicas do livro que serão desenvolvidas nos capítulos seguintes. Primeiramente, ele refere às questões centrais do estudo, expondo também alguns fatos da economia mundial. Dentre elas, a forte dependência do crescimento produtivo ao uso de recusos naturais não-renováveis.

Segundo o autor, o sistema capitalista produz crescimento exponencial da atividade econômica. Isso ocorre porque capitalistas visam unicamente ao lucro, sendo esta a variável chave do sistema. Dado que eles competem pela repartição do excedente da economia, os mesmos devem reinvestir uma parcela crescente de seus lucros a fim de permanecerem na posição de capitalistas. Essa rivalidade causa a reinversão dos lucros, aumenta o investimento e o crescimento da economia. Essa foi a tônica do capitalismo: sistema centrado na exploração de uma mão de obra abundante (e barata) e no uso excessivo de recursos naturais. Nenhum sistema precedente atingiu as taxas de crescimento do produto e da população encontradas durante o capitalismo.

O capitalismo contemporâneo depende do uso de petróleo, principal insumo energético. O petróleo é originado de materiais orgânicos (algas e zooplancton) fossilizados em eras passadas como, por exemplo, a Jurássica (169-144 milhões de anos atrás). Por apresentar elevada densidade energética e fácil transporte e armazenagem o sistema mundial é altamente dependente desse recurso natural. Por ser escasso, o autor indica que o pico da produção de petróleo mundial é iminente, acarretando riscos para o crescimento econômico global.

O uso de recursos naturais a fim de alcançar um crescimento econômico sem limites gera automaticamente o aumento das emissões de gases nocivos ao meio ambiente como, por exemplo, o dióxido de carbono $\left(\mathrm{CO}_{2}\right)$ e o metano. Esses gases provocam o aquecimento do planeta, engendrando riscos a várias espécies, bem como a alteração da vida das populações do globo. Desse modo, professor Li indica que há uma contradição entre o capitalismo e a estabilização climática. A principal conclusão de Li é que as ações da China, atual motor do capitalismo global, para contornar as restrições ao seu crescimento serão fundamentais para definir os rumos da economia global.

No Capítulo 2, intitulado China and the Capitalist World System, professor Li tem a tarefa hercúlia de resumir a história do sistema capitalista mundial e sua relação com a China. Sustenta que a história chinesa pode ser abordada analisando-se como os diferentes grupos responderam aos desafios impostos pelo capitalismo mundial. Nesse sentido, a China passou 
de líder mundial em tecnologia e renda per capita até meados de 1500 para uma das economias mais pobres do mundo em 1950.

Algumas condições históricos levaram ao surgimento do capitalismo. Após a queda do império Romano, o oeste europeu foi dividido em estados de aproximadamente igual tamanho, levando a uma intensa disputa pela liderança da região. Essa competição e o financimanento de guerras por parte de grupos capitalistas foi importante para o aumento do comércio de longa distância e dos lucros. A subsequente conquista de Constantinopla pelos Otomanos em 1453, forçou os estados europeus na busca por novas rotas para chegar na Ásia. Como resultado, eles encontraram a América, região abundante em recursos naturais. O fluxo de ouro da América para a Europa engendrou o aumento da quantidade de moeda nas economias da região, o que em última instância gerou um processo inflacionário abrupto acompanhado de massiva redistribuição de renda em favor das elites. Isso forneceu as condição necessárias para o desenvolvimento do capitalismo mundial.

O autor argumenta que a dinâmica mundial baseada na interação entre o centro, a semi-periferia e a periferia, bem como as lutas de classes em diversas esferas, explicam a evolução do sistema mundial. O centro, formado incialmente pelas economias do oeste europeu, beneficiava-se em suas trocas com as economias da semi-periferia, formada pelas economias latino-americanas e do leste europeu. Estas exportavam bens intensivos em trabalho barato e recursos naturais. Nesse contexto, a perferia (semi-colonias da Ásia e África) estavam relegadas à marginalidade do processo de crescimento.

Depois da II Guerra Mundial, o EUA assumem a hegemonia mundial exercendo bastante influência no leste asiático. O crescimento desta região (Japão e Tigres Asiáticos) juntamente com o crescimento ocorrido na Era de Ouro (1950-70), exerceu uma forte pressão na mão de obra que levou ao seu esgotamento. Decorrente disso, aumentou o poder de barganha dos trabalhadores por maiores salários. O crescimento da demanda energética e o pico na produção de petróleo dos EUA aumentaram o poder da semi-periferia, principalmente dos países exportadores de petróleo. Assim, esses eventos resultaram no choque do petróleo e numa crise estrutural. A resposta para a crise de baixa lucratividade foi restaurar a taxa de lucro mundial. Para isso, foi implementado o monetarismo no centro e o neoliberalismo na semi-periferia. A intensão, segundo o autor, era enfraquecer os trabalhadores das economias centrais (restabelecendo a mão de obra barata), via aumento do desemprego, e implementar reformas (sobretudo privatizações) na semi-periferia. Nesse contexto, a China surge como economia abundante em mão de obra barata e recursos naturais, sendo favorecida pela 
realocação de capital mundial (sendo em 2001 aceita no World Trade Organization, WTO). O país recebeu o ingresso de investimentos diretos externos de grande vulto. Desse modo, a economia chinesa torna-se a plataforma de exportações mundiais, e subsequentemente passa a desempenhar o papel de motor do capitalismo mundial. De acordo com o autor, a incorporação da China na economia mundial aumentou o peso da semi-periferia, podendo ter importantes desdobramentos futuros.

Depois de discutir os aspectos históricos da evolução do sistema capitalista global e sua relação com a China, o professor Li apresenta alguns conceitos chave e estatísticas para auxiliar na compreensão do restante do livro. Partindo dos conceitos básicos de que energia pode apenas ser tranformada e dos tipos de energia (térmica, gravitacional, elétrica e nuclear), professor Li chega aos conceitos de consumo primário e final de energia. $\mathrm{O}$ consumo final resulta do consumo primário descontado das perdas energéticas decorrentes das mudanças de estados físicos, de processamento, de transporte e de transmissão. Logo, a energia disponível para consumo final será sempre menor que a energia primária ofertada.

Em 2010, o autor argumenta que aproximadamente 33\% da energia foi perdida por uma dessas razões. Para este mesmo ano, o consumo final mundial estava dividido em 50\% em petróleo (e bio-combustíveis), $18 \%$ em gás natural, $11 \%$ em carvão e $21 \%$ em eletricidade. Destaca-se a importância do petróleo no consumo final mundial.

Especificamente para a China, o carvão representa 34\%, o petróleo $32 \%$, o gás natural $6 \%$, e a eletricidade $25 \%$ do consumo final de energia em 2010. A dependência da economia chinesa com o carvão fica evidente com a análise dos dados estatísticos. A China consumiu de energia primária o equivalente a $26 \%$ da produção mundial, sendo $73 \%$ disso carvão. $\mathrm{O}$ consumo final de energia do país representa $57 \%$ do consumo primário, realçando a ineficiência de um sistema baseado no carvão.

No período 2000-2012, o consumo mundial de petróleo cresceu a uma taxa anual média de 1,2\%. Petróleo é fundamental para o transporte, a agricultura, o processamento de alimentos, para a produção de pesticidas, de solventes, de fertilizantes, de herbicidas e para a produção de embalagens. A incapacidade das energias renováveis em produzir combustível líquido é um entrave para o crescimento da economia. Dentre as fontes não renováveis, o gás natural é fundamental para iniciar plantas de energia elétrica. Cerca de $22 \%$ do total de energia elétrica disponível provém do uso de gás natural. Ela também serve como um back up para energia solar e eólica. O gás também é um insumo para a indústria química (fertilizantes). O carvão (abundante e barato) em termelétricas representou $41 \%$ de toda a 
energia gerada, além de ser fundamental para a produção de aço. Em 2010, a China representou 50\% do consumo mundial de carvão.

A produção de eletricidade mundial é dependente de fontes não renováveis. Aproximadamente $67 \%$ da produção de eletricidade advém do carvão, do gás natural e do petróleo. Segundo o autor, não há sinal de uma conversão aos renováveis dado que a parcela de energia renovável total- eletricidade mundial caiu de 22\% em 1980 para 20\% em 2010. Ademais, os limites para melhoria da eficiência enérgetica são evidentes. Seu nível depende de como o consumo final de energia é dividido entre os setores econômico, da posição geográfica do país, da divisão do trabalho internacional, e da própria eficiência dos setores.

Em conclusão, o crescimento econômico global depende substancialmente do consumo de energia não renovável (94\% baseado em combustíveis fósseis). Isto somado à incapacidade de produção de combustíveis líquidos a partir de fontes renováveis e do limite do crescimento da eficiência energética (PIB/consumo de energia primária) levará necessariamente à catastrofe ecológica. Dado o pico na produção de petróleo ser iminente (e a alta dependência do mesmo, $50 \%$ do consumo energético final) o uso dos renováveis terá de aumentar, impossibilitando o crescimento exponencial da atividade econômica global, impondo limites ao capitalismo.

No capítulo 4, intitulado Peak Oil, Li examina a hipótese de haver um pico na produção de petróleo mundial, baseado no procedimento desenvolvido por Marion King Hubbert, geólogo que previu o pico na produção de petróleo para a economia americana na década de 70. Professor Li inicia o capítulo procedendo regressões lineares para o período 1981-2012, a fim de verificar a relação entre o crescimento econômico mundial e a alteração do consumo de petróleo. Encontra que caso a produção de petróleo atinja um pico, a taxa de crescimento da economia cairá para 1,6\%. Este número está abaixo do limiar histórico de $2 \%$ relacionado com crises econômicas. De forma análoga, o autor executa uma regressão da taxa de crescimento do consumo de petróleo pela China em função de seu crescimento econômico. Desta vez, observa que o crescimento de $1 \%$ da economia gera um crescimento de $0,54 \%$ no consumo de petróleo.

Empregando o procedimento desenvolvido por Hubbert, o autor estima a relação entre a taxa de crescimento da produção de petróleo acumulada com sua produção acumulada. Sua estimação indica que o pico de produção mundial deve ocorrer em meados de 2018, considerando inovações teconológicas constantes no período. Suas projeções são compatíveis 
com o fato de que dos 20 maiores campos de petróleo do mundo, 16 já atingiram o pico de produção.

Posteriormente, Li analisa as economias dos maiores importadores (China e EUA) e exportadores (Rússia e Arábia Saudita) de petróleo. Argumenta que os países exportadores dependem do produto para financiar o orçamento público e para atingir suas metas de crescimento. Em contraste, os países importadores dependem do baixo preço da commodity para crescer. $\mathrm{O}$ grande dilema apontado pelo autor refere-se à projeção de que o preço para os importadores (que garante estabilidade social e garante o crescimento econômico) será inferior ao preço esperado pelos fornecedores do produto para estimular o crescimento produtivo. Esse descompasso é um indicativo de crise para o futuro do capitalismo.

Professor Minqi Li apresenta uma análise da relação entre o pico na produção de energia e os limites para o crescimento econômico global no Capítulo 5. Nele, o autor examina as principais fontes de energia mundial. Depois de constatar que a oferta mundial de energia é dependente de recursos não renováveis, o mesmo refere que energias renováveis alternativas dependem do uso intensivo de terra e recursos minerais. Segundo Li, a oferta de energia renovável não pode ser ofertada sem limites, uma vez que depende de recursos escassos. Por exemplo, a energia nuclear é dependente das reservas de urânio, um mineral escasso e não renovável. Ademais, energias renováveis apenas produzem eletricidade. Isso impõe um limite para o uso dessas fontes de energia.

Segundo as projeções do autor, a oferta mundial de petróleo atingirá um pico antes de 2020, a de gás natural em meados de 2034, e a produção de carvão alcançará seu auge em 2044. A oferta nuclear atingirá o pico em 2090, com todos os riscos inerentes a produção desse tipo de energia. Nesse sentido, o consumo mundial de energia atingirá um pico em 2060 .

Nesse contexto, o pico na produção de energia acarretará o aumento dos preços, reduzindo a lucratidade, o investimento e o crescimento econômico. O capitalismo mundial seria imcompatível com esse cenário.

Em seguida, no capítulo intitulado Peak Energy and the Limits to China's Economic Growth, Li faz uma análise análoga ao capítulo anterior com foco na China. Segundo Li, a China enfrentará problemas para viabilizar seu crescimento em três esferas: habilidade para aumentar a produção de energia, capacidade para importar uma parcela crescente da produção de energia mundial, e aumentar a eficiência energética. 
O país depende da produção de carvão, seu consumo de energia primária em 2012 foi composto de $73 \%$ de carvão, cuja produção atingirá um pico em 2026. De acordo com o autor, o petróleo que representa 19\% do consumo atingirá um pico em 2023, e o gás natural (5\%) terá um pico em 2045. Isto conjuntamente sugere que a capacidade do país aumentar a produção de energia será bastante limitada num futuro próximo.

Segundo as projeções de Li, o consumo de energia da China chegará ao pico no início da década de 2030. A parcela do carvão aumentará na produção total de energia, sendo o crescimento chinês projetado para arrefecer entre 2015 e 2050. Depois de 2050, o autor acredita que a economia chinesa entrará numa fase de crescimento com taxas quasi- steady state, convergindo com o passar do tempo ao crescimento nulo.

Professor Li análisa o crescimento chinês no Capítulo 7, intitulado The Crisis of Chinese Capitalism. O autor realça as contradições econômicas, sociais, e ecológicas que levarão à crise estrutural da economia chinesa.

O modelo de crescimento do país, baseado na exploração de mão de obra barata e na degradação de combustíveis fósseis (principalmente carvão), chegará ao esgotamento. Este ocorrerá pela insuficiência da oferta de mão de obra (dada a exaustão do processo migratório campo-cidade) e do declínio na oferta de recursos naturais. O declínio da oferta de energia e o aumento das demandas econômicas, sociais e políticas por parte dos trabalhadores, engendrará a queda da taxa de lucro. Como o capitalismo visa a produção para gerar lucros, o resultado final será a crise da economia.

O aumento do poder dos trabalhadores e o colapso ecológico da China levará à crise do país. Logo, haverá o conflito entre o crescimento chinês baseado em acumulação crescente e sustentabilidade ambiental. Segundo o autor, a China representa o elo mais fraco da economia capitalista mundial, sendo o futuro da economia global condicionado à forma como o país enfrentará esses desafios. Li projeta uma crise global em meados de 2020.

Na sequência, o autor mostra que somente o crescimento econonômico zero evitará catástrofes ecológicas em escala global. Isto envolve a descarbonização da China, tendo em vista seu papel na economia mundial. O impacto da atividade humana sobre o meio ambiente deve ser minimizado, levando em conta a capacidade de regeneração do sistema, bem como sua capacidade de absorção.

Nesse sentido, o autor argumenta que o impacto da continuidade do modelo capitalista acarretará no aumento da temperatura em aproximadamente $3^{\circ} \mathrm{C}$ (com relação ao nível préindustrial) no planeta, podendo destruir a floresta amazônica e impactando negativamente 
(dado o aumento do nível do mar) países como a Austrália, os países do mediterrâneo, e a África do Sul. Nesse cenário, um dos principais carbon sinks (as algas) morrerão e haverá a queda da população.

Uma possível solução para evitar o aquecimento global seria a cooperação internacional. Contudo, os países competem intensamente entre si em busca do crescimento econômico no sistema capitalista global, deixando em segundo plano qualquer mudança que afete negativamente suas perspectivas de crescimento. A política individual de redução da utilização de combustíveis fosseis comprometerá o crescimento de curto prazo do país, sendo os benefícios da redução de emissões compartilhados por todos os países. Em outras palavras, os custos do desaquecimento são privados, enquanto os benefícios são socializados com todos os países. Esse dilema resulta na impossibilidade de resolução do problema via cooperação internacional dentro do sistema capitalista mundial. Segundo o autor, a solução para esse impasse passa pela mudança do regime mundial para um sistema que não vise o crescimento econômico.

Por fim, no último capítulo, o autor sugere que o socialismo seria compatível com a sustentabilidade ecológica. A economia poderia funcionar com crescimento em estado estacionário, havendo a socialização dos investimentos e dos meios de produção. Isto envolveria o uso do excedente em projetos ambientais, além do gasto em educação e saúde na China. Assim, professor Li indica que o excedente deve ser concentrado em consumo social, indicando que o socialismo seria um sistema viável, compatível com a restrição ambiental.

\section{Considerações finais}

O fechamento do livro destaca e resume as principais partes do texto, reforçando as teses desenvolvidas por Li. Nesta parte, o autor salienta que o sistema capitalista possui como única meta a busca por lucros via acumulação crescente, não existindo mecanismo de correção intena ao sistema a fim de evitar a degradação ambiental. O sistema por ser excessivamente explorador de trabalho e recursos naturais, consegue gerar o crescimento exponencial da economia. Apesar do sistema gerar inovações tecnológicas, as mesmas dependem de recursos escassos impondo novos limites e crises. Para Li, capitalismo e estabiliadade ecológica são contraditórios.

Para o autor, a descarbonização da China e a mudança do regime global para o socialimo são condições necessária para a estabilidade climática do planeta. Nesse sentido, a mudança no rumo da economia chinesa será crucial para evitar uma catástrofe ecológica. 
Somente um sistema compatível com crescimento nulo da economia garantirá a sustentabilidade ecológica do planeta.

Embora não cite em sua obra, as conclusões do autor quanto à insustentabilidade do sistema capitalista podem ser associadas ao Paradoxo de Jevons, segundo o qual inovações tecnológicas tornam máquinas e equipamentos individualmente mais eficientes no uso dos recursos naturais, porém com o sistema aumentando sua escala de produção globalmente o consumo desses materiais escassos tendem a aumentar substancialmente.

\section{Referências}

ARRIGHI, G. The long twentieth century: money, power and the origins of our times. London: Verso, 2010. 416 p.

FOSTER, J. B. The ecological rift: capitalism's war on the earth. New York: Monthly Review Press, 2010. 544 p.

LI, M. The rise of China and the demise of the capitalist world economy. London: Pluto Press, 2009. 208 p.

MARX , K. Capital, Volume III. New York: International Publisher. 1081 p.

TUCKER, R. C. The Marx-Engels Reader. New York: W.W. Norton \& Company, 1972. $788 \mathrm{p}$.

WALLERSTEIN, I. The Capitalist Worl Economy: Essays by Immanuel Wallerstein. Cambridge: Cambridge University Press, 1979. 305 p. 